\title{
Relationships between the parasitic mite Spinturnix andegavinus (Acari: Spinturnicidae) and its bat host, Myotis daubentonii (Chiroptera: Vespertilionidae): seasonal, sex- and age-related variation in infestation and possible impact of the parasite on the host condition and roosting behaviour
}

\author{
Radek K. Lučan \\ Department of Zoology, Faculty of Biological Sciences, University of South Bohemia, Branišovská 31, 37005 České \\ Budějovice, Czech Republic
}

Key words: Spinturnix, bats, parasites, body condition, Chiroptera, Myotis daubentonii

\begin{abstract}
Host-parasite relationships between the Daubenton's bat, Myotis daubentonii Kuhl, 1817 (Chiroptera: Vespertilionidae), and its haematophagous ectoparasite, the mite Spinturnix andegavinus Kolenati, 1857 (Acari: Spinturnicidae), were subjected to analyses based on data gathered during a six-year study (1999-2004) within a single study area in South Bohemia, Czech Republic. Seven hundred and fifty-one Daubenton's bats were examined by screening wing membranes with an intensive light source, resulting in 4,690 recorded mites. Sex, age, weight and reproductive state were evaluated for each bat. A body condition index was calculated as a ratio of weight to forearm length. The seasonal course of mite infestation displayed distinct dynamics with the peak during the lactation and post-lactation periods coinciding with occurrence of the most numerous colonies of Daubenton's bats in the study area. Infestation rates differed between the two sexes, being higher in adult females than adult males. Juvenile bats of both sexes (with no differences between males and females) were the most infested group of all. Pregnant females had a significantly higher parasite load than non-pregnant ones, while no differences in infestation rates were found between lactating and non-lactating females. The analyses of the relationship between parasite load and body condition of bats revealed no common trends for all sex- and age-related groups. Two possible explanations are suggested and discussed: (1) There is no true relationship between the two tested variables and, thus, the significant results were attained due to a random statistical effect. (2) Different underlying causal mechanisms may exist that influence parasite load and, especially, body condition, with respect to the particular sex and age category of bats. The seasonal roosting dynamics of the Daubenton's bat are suggested to be the result not only of changing energetic demands of resident population members, but also of coevolutionary strategies within host-parasite relationships.
\end{abstract}

Although bat ectoparasites have been studied extensively during the last few decades, information concerning host-parasite relationships is scarce. So far, most studies on bat ectoparasites dealt with either their taxonomy and/or their faunistics; few papers describe life cycles (cf. Dusbábek 1972, Estrada-Peña and SerraCobo 1991, Estrada-Peña et al. 1991,) or even relationship between ectoparasite density and reproductive cycle of its bat host (Dietz and Walter 1995, Christe et al. 2000). Also, the causal mechanisms underlying host specificity in bat ectoparasites remains poorly understood with only two studies being published just recently (Christe et al. 2003, Giorgi et al. 2004).

Ectoparasites reduce the reproductive success and survival of hosts and thereby exert selection pressure on host life-history traits. Although the negative effect of ectoparasitism on fitness was studied in variety of animals (e.g. barn swallows, Møller 1990; voles, Okulova and Aristova 1973; horses, Rubenstein and Hohmann 1989), very little data have been available in the case of bats (see Marshall 1982). There are only several bat species in which the impact of spinturnicid mites on their body condition or energy budget was analysed (Lewis 1996, Giorgi et al. 2001, Zahn and Rupp 2004, Laurenço and Palmeirim 2005).

Mites of the genus Spinturnix (Acari: Spinturnicidae) are ectoparasites of microbats, formerly classified under the suborder Microchiroptera (Rudnik 1960). They occur on the chiropteropatagium of bats and complete their entire life cycle on their hosts. Few studies have been published to date on the biology of spinturnicid mites, except those dealing with taxonomy and faunistics. Moreover, most published data were not collected from one locality or population but from within larger geographical and time scales, and thus the reported variability in these datasets often restricts the interpretation value of observed phenomena (cf. e.g. Zahn and Rupp 2004).

In the present study I summarise temporal variation in infestation and prevalence of the ectoparasitic mite Spinturnix andegavinus (Kolenati, 1857), with respect to sex, age, reproductive state and roosting dynamics of 
its host, the Daubenton's bat (Myotis daubentonii Kuhl, 1817). The possible impact of parasitation on body condition of bats is also analysed in the context of current view of host-parasite biology.

Although the precise taxonomical position of spinturnicid mites infesting $M$. daubentonii is still to be resolved (see Uchikawa et al. 1994), the name $S$. andegavinus sensu Deunff (1977) and Estrada-Peña and Sanchez (1989) is used in this study. Some authors do not consider $S$. andegavinus an independent species, separated from Spinturnix myoti (cf. Baker and Craven 2003). Since $S$. andegavinus represents the only spinturnicid species infesting Daubenton's bats (Deunff and Beaucournu 1981, Rupp et al. 2002), the collection and determination of individual mites was performed only incidentally to ascertain literature data. Indeed, in all cases only $S$. andegavinus was found.

\section{MATERIALS AND METHODS}

The present study was carried out in the northern part of Třeboň Basin Protected Landscape Area and Biosphere Re-

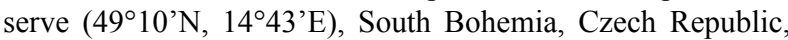
from 1999 until 2004. Daubenton's bats in the study area roost almost exclusively in tree holes excavated by woodpeckers (Picidae). The only exception was represented by a small abandoned cellar-like building formerly used as a limekiln. This building has been used as a roost by a bat colony numbering up to 120 individuals for more than 40 years (Hanák, pers. comm.). In total, 58 tree cavities were discovered and their inhabitation by bats during the reproduction season was monitored either by catching emerging bats in special traps placed in front of the entrance or by listening to the typical vocalisation of bats before evening departure. An ultrasound bat-detector was then used to confirm the accuracy of identification. Captured bats were sexed, aged, weighted to the nearest $0.5 \mathrm{~g}$ and their forearm length was measured to the nearest $0.1 \mathrm{~mm}$. Subadult bats (i.e. individuals after their first winter that have not reproduced yet) were distinguished by a typical black spot on the lower chin (Richardson 1994). Pregnancy was estimated through a gentle palpation of the abdomen. Lactating females were identified according to enlarged nipples and fur absence in the nipple surroundings. All bats were marked with aluminium rings. Up to five recaptures were recorded during the study period.

The number of ectoparasitic mites was counted by screening wing membranes of the bats with an intensive light source. In total, 751 bats were examined from which 4,690 mites were recorded.

The particular season (= year) was subdivided onto five periods according to reproductive state of bat population under the study: spring movement period - until May 10, prelactation period - until June 10, lactation period - until July 10, post-lactation period - until August 15, autumn movement period - after August 15. Since data from some periods are not available for all years, the variation in parasite load among years was not analysed.

Multiple analyses of variance were performed to reveal differences in infestation rates among sex, age and reproduction classes of bats. Spearman's rank-correlation coefficient was used to examine the relationship between roosting dynamics of bats and mean parasite load. To evaluate the impact of parasites on bats, body condition was calculated for each bat, indexed as the ratio of weight to forearm length (Lewis 1996). To include the impact of different energy budgets of reproductive and non-reproductive females (cf. Racey and Speakman 1987), these two groups were not united for this analysis. Spearman's rank-order correlation coefficient was then used to examine the relationship between the body condition index of individual bats and their parasite load. Data analyses were performed using STATISTICA 6.0 (StatSoft, Inc.).

\section{RESULTS}

\section{Seasonal differences}

The period of Daubenton's bat reproductive cycle had a significant impact on infestation rates of mites $(\mathrm{F}$ $=78.276$, d.f. $=4, \mathrm{n}=751, \mathrm{p}<0.0001)$. Relatively low parasite loads occurred during the spring and autumn movement periods and the pre-lactation period. Rapid increase of parasite load was recorded during summer months with a peak in the lactation period (Fig. 1).

Daubenton's bats in the study area form the most numerous colonies mainly during the post-lactation period, and thus seasonal dynamics of parasite load is positively related to the roosting dynamics of the host. More precisely, the mean number of mites per bat was significantly correlated with the size of bat colonies from which they were obtained $\left(\mathrm{r}_{\mathrm{s}}=0.57, \mathrm{p}=0.0001, \mathrm{n}\right.$ $=39$ ), when periods of host reproductive cycle were not taken into account. This correlation simply depicts the seasonal course of the numbers of mites found on bats in relation to seasonal changes in sizes of bat colonies, i.e. bats were most heavily parasitized in the periods in which they formed the largest colonies. By contrast, no relation was proven between the mean infestation rate per colony and colony size (i.e. host density) within the autumn movement sample, the only period for which a sufficient amount of data for this kind of analysis was available $\left(\mathrm{r}_{\mathrm{s}}=0.29, \mathrm{p}=0.257, \mathrm{n}=17\right)$.

Prevalence of mites fluctuated during the season as shown in Table 1. The highest prevalence was recorded in the lactation period, when all examined bats possessed at least 1 mite (100\% prevalence). Also, there was an obvious trend toward higher prevalence in females than males during the spring movement period.

\section{Impact of sex, age and reproductive state}

There were no differences in infestation rates between subadult and adult bats $(\mathrm{F}=0.958$, d.f. $=1, \mathrm{n}=$ $525, \mathrm{p}=0.328)$, therefore they were evaluated as one group ("adults") in further analyses.

A strong impact of sex and age on parasite load was proven by analyses. Adult females hosted significantly more parasites than males $(\mathrm{F}=11.315$, d.f. $=1, \mathrm{n}=434$, $\mathrm{p}<0.0001)$.

On average, juveniles were much more infested than adults $(\mathrm{F}=22.648$, d.f. $=1, \mathrm{n}=585, \mathrm{p}<0.0001)$, hosting as many as 36 mites per individual. In contrast to 


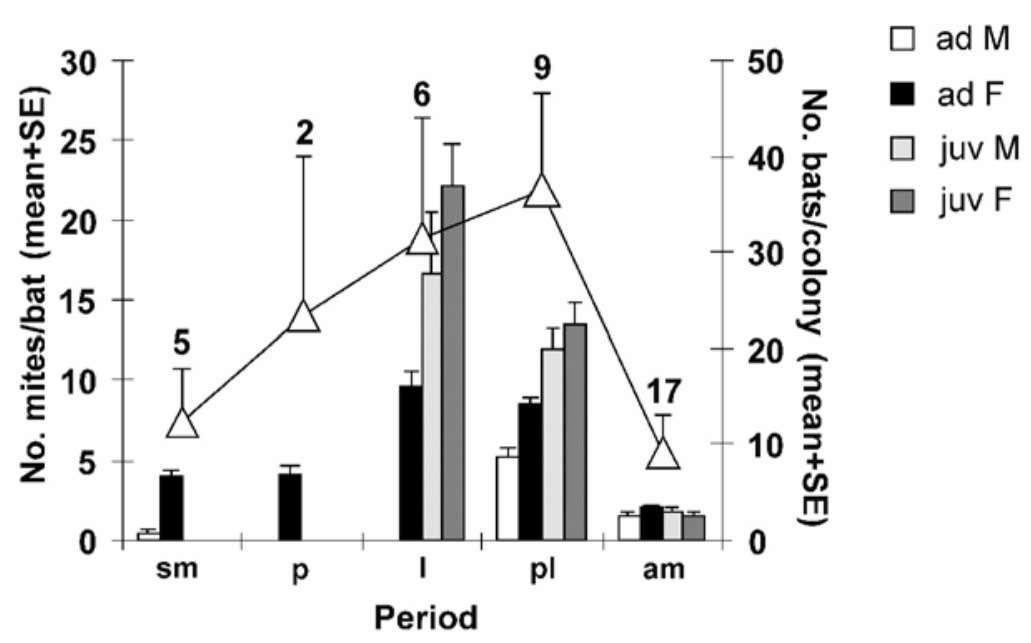

Fig. 1. Parasite load in particular sex and age classes of Daubenton's bats (Myotis daubentonii) by Spinturnix andegavinus during season (bars) along with sizes of sampled bat colonies (lines). Numbers above triangles with whiskers denote sample sizes. Periods: sm - spring movement period, $\mathrm{p}$ - pre-lactation period, 1 lactation period, $\mathrm{pl}$ - post-lactation period, am - autumn movement period. Ad M adult males, ad $\mathrm{F}$ - adult females, juv $\mathrm{M}$ juvenile males, juv $\mathrm{F}$ - juvenile females.

Table 1. Prevalence of Spinturnix andegavinus in particular sex and age classes of Daubenton's bats (Myotis daubentonii) during five periods of its reproductive cycle. The numbers in parentheses represent the total numbers of bats examined and the total numbers of mites counted, respectively. Ad M - adult males, ad F - adult females, juv $\mathrm{M}$ - juvenile males, juv F - juvenile females.

\begin{tabular}{|l|c|c|c|c|}
\hline \multirow{2}{*}{ Period } & \multicolumn{4}{|c|}{ Prevalence } \\
& ad M & ad F & juv M & juv F \\
\hline Spring movement & $25 \%(12,5)$ & $86 \%(51,205)$ & - & - \\
Pre-lactation & - & $81 \%(47,194)$ & - & - \\
Lactation & - & $100 \%(43,413)$ & $100 \%(5,83)$ & $100 \%(8,177)$ \\
Post-lactation & $96 \%(28,140)$ & $95 \%(198,1,679)$ & $100 \%(52,636)$ & $100 \%(52,698)$ \\
Autumn movement & $71 \%(25,35)$ & $81 \%(122,249)$ & $68 \%(53,91)$ & $67 \%(57,85)$ \\
\hline
\end{tabular}

adult bats, there were no differences in parasite load between the two sexes in juveniles $(F=2.345$, d.f. $=1$, $\mathrm{n}=227, \mathrm{p}<0.127)$. Marked differences in parasite load between adult and juvenile bats diminished in the autumn movement period.

Pregnant females hosted significantly more parasites $(4.6 \pm 0.5)$ than non-pregnant females $(0.8 \pm 0.5)$ in the pre-lactation period $(\mathrm{F}=7.10$, d.f. $=1, \mathrm{n}=46, \mathrm{p}<0.01)$. These differences diminished during the lactation period, when lactating and non-lactating females did not differ in parasite load $(\mathrm{F}=1.753$, d.f. $=1, \mathrm{n}=43, \mathrm{p}=$ $0.193)$ with mean $( \pm \mathrm{SE})$ infestation rates $10.3 \pm 1.1$ and $7.1 \pm 2.0$, respectively.

\section{Impact of parasitation on body condition of bats}

Only the periods with a sufficient amount of data (the post-lactation and the autumn movement period) were analysed. In most cases, Spearman's correlation coefficient did not reveal any significant relationship between number of parasites and the body condition index of bats. A positive correlation of parasite load and the body condition index was found in adult $\left(\mathrm{r}_{\mathrm{s}}=0.22, \mathrm{p}<0.05\right.$, $\mathrm{n}=118)$ and subadult females $\left(\mathrm{r}_{\mathrm{s}}=0.41, \mathrm{p}<0.05, \mathrm{n}=\right.$ 32) during post-lactation period. In contrast, negative relation of body condition to parasite load was proven in juvenile males $\left(\mathrm{r}_{\mathrm{s}}=-0.44, \mathrm{p}<0.01, \mathrm{n}=46\right)$ and juvenile females $\left(r_{s}=-0.49, p=0.001, n=49\right)$ in post-lactation period and, also, in juvenile females $\left(\mathrm{r}_{\mathrm{s}}=-0.3, \mathrm{p}<0.05\right.$, $\mathrm{n}=45$ ) in the autumn movement period.

\section{DISCUSSION}

Infestation rates as well as prevalence of Spinturnix andegavinus are clearly dependent on the period of reproductive season of its bat host. Low parasite numbers were found on individual bats during the spring and autumn movement periods, whereas an increase in both infestation rates and prevalence occurred in the lactation and post-lactation periods. The results of analogical studies, mostly of other species of spinturnicid mites, had often revealed concordant patterns in seasonal changes in infestation rates. Thus, Dietz and Walter (1995) reported a similar pattern in seasonal infestation of German populations of Daubenton's bats by $S$. andegavinus. Also, Deunff and Beaucournu (1981) found the highest intensities as well as prevalence of Spinturnix myoti during June and July on Myotis myotis, with mean infestation rates about 20 mites per bat and the prevalence of $100 \%$. The highest numbers of Spinturnix psi on Miniopterus schreibersii were found at the end of June (Estrada-Peña et al. 1991). Just recently, Zahn and Rupp (2004) recorded a discrepancy in synchronisation of seasonal changes in parasite load on Daubenton's bats among different sites and years in Bavaria. Nevertheless, the highest infestation rates occurred particularly during summer months.

This trend toward higher abundance of $S$. andegavinus during the summer season could be associated with its host's life strategy. Host density seems to be an im- 
portant factor explaining distribution and abundance of parasites (Arneberg et al. 1998, Morand and Poulin 1998, Morand 2000, Poulin and Morand 2000, Stanko et al. 2002). An increase in density, as it may co-vary with the expansion of social group size, is likely to increase the amount of contact between individuals, and to favour the transmission of parasites; this was confirmed by using a meta-analysis by Côté and Poulin (1995).

Daubenton's bats in the study area form numerous maternity colonies in the course of May. Nevertheless, the most numerous colonies (over 80 individuals) were found in July shortly after the weaning of juveniles (Lučan and Hanák 2002), coinciding with the highest infestation rates of mites.

The fragmentation of Daubenton's bat colonies and their disintegration into higher numbers of less numerous aggregations, hand in hand with the occupation of new roosts shortly after the breeding period (from midAugust onward), was observed in the study area (Lučan 2001, Lučan and Hanák 2002). This pattern could be a consequence of changing energetic demands of members of the resident Daubenton's bat population (e.g. Racey and Speakman 1987) during the season as well as antiparasitic roosting behaviour. Although spinturnicid mites spend their entire life cycle on bat wing membranes, they have been found in great numbers away from bats on the guano within the roost (Deunff and Beaucournu 1981). Therefore, bats could benefit from switching roosts. Moreover, there are many other ectoparasites such as cimicids and ischnopsyllids infesting the Daubenton's bat, which may also be effectively avoided by roost switching. Indeed, a rapid decrease in the numbers of mites on bats occurred during the time following the disintegration of numerous maternity colonies into less numerous transient and mating aggregations in the autumn movement period.

The extensiveness and intensity of infestation as well as the number of parasite species are usually somewhat higher in females and juveniles than in males and subadult specimens (Dusbábek 1972, Estrada-Peña et al. 1991, Chilton et al. 2000, Zahn and Rupp 2004). Males and non-reproductive females generally roost individually or in small aggregations away from maternity colonies (Hamilton and Barclay 1994) and may avoid ectoparasites or reduce infestation by frequently switching day roosts (Lewis 1996). In contrast, female bats usually form large maternity colonies and thus provide good opportunities for the horizontal transmission of parasites (e.g. Chilton et al. 2000).

Spinturnicid mites adjust their reproductive cycle to that of the host by massively infesting newborns, very vulnerable hosts (Christe et al. 2000). Newborns as well as juvenile bats are considered more attractive for parasites than adults because of less self-grooming proficiency (McLean and Speakman 1997). Exactly the same situation was observed in the case of Daubenton's bat during my study. During or shortly after weaning, juve- niles hosted much higher numbers of mites than adults. During the gestation period, gravid females were more infested than non-reproductive females, while no differences in infestation rates were found during lactation. A similar pattern was observed in Myotis myotis (Christe et al. 2000), where infestation rates of Spinturnix myoti were negatively correlated with the immunocompetence of females. The differences in infestation rates during pregnancy between gravid and non reproductive females may not have been due to age differences but rather to immunosuppression by sex hormones during gestation as was suggested by Grossman (1985).

The analyses of the relationship between parasite load and body condition of bats revealed no common trends for all sex and age related groups. While parasite load on body condition was found to have no significant impact on adult and subadult males, a positive (but weak) relationship was proven in adult and subadult females during the post-lactation period. In contrast to adult and subadult females, juveniles of both sexes tended to have worse body conditions when possessing higher parasite loads in the post-lactation (both males and females) and autumn movement (females) period. These contrasting results may indicate two possible explanations: (1) There is no true relationship between the two tested variables and, thus, the significant results were attained due to a random statistical effect. (2) There may exist different underlying causal mechanisms that influence parasite load and, especially, body condition, with respect to the particular sex and age category of bats. For example, juvenile bats may display a worse ability to compensate for increased energetic demands imposed by high parasite load (Giorgi et al. 2001) during summer months than adults. The negative impact of ectoparasites may diminish as they improve foraging skills during autumn.

In line with the first hypothesis, no direct evidence of detrimental effects of nycteribiid ectoparasites on bats was observed by Archer and Cardinal (2001). Accordingly, Zahn and Rupp (2004) suggested that high parasite numbers in weak bats did not appear to be a cause but rather a symptom of poor condition of the European bat community.

On the other hand, Lewis (1996) and Giorgi et al. (2001) reported on direct evidence of the detrimental effects of parasitation on body condition with distinct consequences for roosting and grooming behaviour in pallid bats, Antrozous pallidus and greater mouse-eared bats, Myotis myotis, respectively. During their study of the impact of parasitic mites on the condition of the bent-winged bat, Miniopterus schreibersii, Laurenço and Palmeirim (2005) detected significant negative effects of mites on the body condition of bats only in the period with the highest infestation rates. However, heavily parasitized bats had, in general, the worst body condition observed at any time of the year (Laurenço and Palmeirim 2005). 
Finally, the discrepant relationships between the body condition of bats and infestation rates, found during this study, may actually reveal an occurrence of two host-choice strategies in spinturnicid mites within the same host-parasite system, as suggested by Christe et al. (2003). According to this hypothesis, well-fed hosts in good condition (adult females in this study) and vulnerable hosts (juveniles in this study) may represent the two optima for the mites.

Although a largely weak negative effect on body condition was proven by a simple relationship between the body condition index and the number of mites, this may actually represent the minimum energetic impacts of parasitic mites upon their roosting hosts. The possible key role of spinturnicid mites in the transmission of blood parasites could even be of greater importance (Giorgi et al. 2001).
Thus, I suggest that the seasonal roosting dynamics of the Daubenton's bat may be the result of changing energetic demands of resident members of the population as well as coevolutionary strategies within hostparasite relationships.

Acknowledgements. I would like to thank Ivan Horáček and two anonymous referees for their helpful comments on the manuscript of the paper. Also, I would like to thank Marek Stibal and Nick Wright for their help with language improvement of the manuscript. The research was supported by the Mattoni Awards for Studies of Biodiversity and Conservation Biology, by the Faculty of Biological Sciences, University of South Bohemia and the Ministry of Education, Youth and Sports of the Czech Republic (MSM 6007665801) and by the Grant Agency of the Czech Republic (project no. 206/05/ 2334).

\section{REFERENCES}

ARCHER M.S., CARDINAL B.R. 2001: Seasonal reproduction and host infestation rates for nycteribiids of the large bentwing bat. Med. Vet. Entomol. 15: 452-454.

ARNEBERG P., SKORPING A., GRENFELL B., READ A.F. 1998: Host densities as determinants of abundance in parasite communities. Proc. R. Soc. Lond., Ser. B., 265: $1238-1289$

BAKER A.S., CRAVEN J.C. 2003: Checklist of the mites (Arachnida: Acari) associated with bats (Mammalia: Chiroptera) in the British Isles. Systematic \& Applied Acarology Special Publications 14: 1-20.

CHILTON G., VONHOF M.J., PETERSON B.V., WILSON N. 2000: Ectoparasitic insects of bats in British Columbia, Canada. J. Parasitol. 86: 191-192.

CHRISTE P., ARLETTAZ R., VOGEL P. 2000: Variation in intensity of a parasitic mite (Spinturnix myoti) in relation to the reproductive cycle and immunocompetence of its bat host (Myotis myotis). Ecol. Lett. 3: 207-212.

CHRISTE P., GIORGI M.S., VOGEL P., ARLETTAZ R. 2003: Differential species-specific ectoparasitic mite intensities in two intimately coexisting sibling bat species: resource-mediated host attractiveness or parasite specialization? J. Anim. Ecol. 72: 866-872.

CÔTÉ I.M., POULIN R. 1995: Parasitism and group size in social animals: a meta-analysis. Behav. Ecol. 6: 159-165.

DEUNFF J. 1977: Observations sur Spinturnicidae de la region palearctique occidentale (Acarina, Mesostigmata). Specificité, repartition et morphologie. Acarologia 18: 602-617.

DEUNFF J., BEAUCOURNU J.-C. 1981: Phénologie et variations du dermecos chez quelques espèces de Spinturnicidae (Acarina: Mesostigmata). Ann. Parasitol. Hum. Comp. 56: 203-224.

DIETZ M., WALTER G. 1995: Zur Ektoparasitenfauna der Wasserfledermaus (Myotis daubentonii Kuhl, 1819) in Deutschland unter der besonderen Berücksichtigung der saisonalen Belastung mit der Flughautmilbe Spinturnix andegavinus Deunff, 1977. Nyctalus 5: 451-468.

DUSBÁBEK F. 1972: The zone of bat acarinia in Central Europe. Folia Parasitol. 19: 139-154.
ESTRADA-PEÑA A., PERIBÁÑEZ M.A., SERRA J. 1991: The life cycle of Spinturnix psi (Mesostigmata: Spinturnicidae) on Miniopterus schreibersii (Mammalia: Chiroptera). In: F. Dusbábek and V. Bukva (Eds.), Modern Acarology. Vol. 2. Academia, Prague and SPB Academic Publishing bv, The Hague, pp. 475-480.

ESTRADA-PEÑA A., SANCHEZ C. 1989: Redescription of Spinturnix dasycnemi (Kolenati) (Acarina: Spinturnicidae). Acarologia 30: 107-110.

ESTRADA-PEÑA A., SERRA-COBO J. 1991: The acarinia and nycteribidia zones of Miniopterus schreibersii Kuhl (Mammalia: Chiroptera) in the northeast of Spain. Folia Parasitol. 38: 345-354.

GIORGI M.S., ARLETTAZ R., CHRISTE P., VOGEL P. 2001: The energetic grooming costs imposed by a parasitic mite (Spinturnix myoti) upon its bat host (Myotis myotis). Proc. R. Soc. Lond., Ser. B., 268: 2071-2075.

GIORGI M.S., ARLETTAZ R., GUILLAUME F., NUSSLÉ S., OSSOLA C., VOGEL P., CHRISTE P. 2004: Causal mechanisms underlying host specificity in bat ectoparasites. Oecologia 138: 648-654.

GROSSMAN C.J. 1985: Interactions between gonadal steroids and the immune system. Science 227: 257-267.

HAMILTON I.M., BARCLAY R.M.R. 1994: Patterns of daily torpor and day-roost selection by male and female big brown bats (Eptesicus fuscus). Can. J. Zool. 72: 744-749.

LAURENÇO S.I, PALMEIRIM J.M. 2005: Can parasitic mites affect the condition of bat hosts? The case of Spinturnicidae on the bent-winged bat. Abstracts of the 10th European Bat Research Symposium, Galway, Ireland, $21^{\text {st }}$ $-26^{\text {th }}$ August 2005.

LEWIS S.E. 1996: Low roost-site fidelity in pallid bats: associated factors and effect on group stability. Behav. Ecol. Sociobiol. 39: 335-344.

LUČAN R. 2001: Population biology of Daubenton's bat, Myotis daubentonii (Kuhl, 1817) in Třeboň Basin. Bc. Diploma work, Faculty of Biological Sciences, University of South Bohemia, České Budějovice, 44 pp. (Unpubl., in Czech with English abstract.) 
LUČAN R., HANÁK V. 2002: A long term study of population of Daubenton's bat Myotis daubentonii. Abstracts of $9^{\text {th }}$ European Bat Research Symposium, Le Havre, 26-30 August 2002, p. 42.

MARSHALL A.G. 1982: Ecology of insects ectoparasitic on bats. In: T.H. Kunz (Ed.), Ecology of Bats. Plenum, New York, pp. 369-401.

McLEAN J.A., SPEAKMAN J.R. 1997: Non-nutritional maternal support in the brown long-eared bat. Anim. Behav. 57: 1193-1204.

MøLLER A.P. 1990: Effect of parasitism by a hematophagous mite on reproduction in the barn swallow. Ecology 71: 2345-2357.

MORAND S. 2000: Wormy world: comparative tests of theoretical hypotheses on parasite species richness. In $\mathrm{R}$. Poulin, S. Morand and A. Skorping (Eds.), Evolutionary Biology of Host-Parasite Relationships: Theory Meets Reality. Elsevier, Amsterdam, pp. 63-79.

MORAND S., POULIN R. 1998: Density, body mass and parasite species richness of terrestrial mammals. Evol. Ecol. 12: 717-727.

OKULOVA N.M., ARISTOVA V.A. 1973: Influence of ectoparasites on a population of the northern red-backed vole in southwestern Siberia. Sov. J. Ecol. 4: 522-527. (In Russian.)

POULIN R., MORAND S. 2000: The diversity of parasites. Quart. Rev. Biol. 75: 277-293.

Received 24 February 2005
RACEY P.A., SPEAKMAN J.R. 1987: The energy cost of pregnancy and lactation in heterothermic bats. Symp. Zool. Soc. Lond. 57: 107-125.

RICHARDSON P.W. 1994: A new method of distinguishing Daubenton's bats (Myotis daubentonii) up to one year old from adults. J. Zool. 233: 307-309.

RUBENSTEIN D.I., HOHMANN M.E. 1989: Parasites and social behavior of island feral horses. Oikos 55: 312-320.

RUDNIK A. 1960: A revision of the family Spinturnicidae (Acarina). Univ. Calif. Publ. Entomol. 17: 157-284.

RUPP D., ZAHN A., LUDWIG P. 2002: Some faunistical aspects of the ectoparasite load on Bavarian bats. Abstracts of $9^{\text {th }}$ European Bat Research Symposium, Le Havre, 26-30 August 2002, p. 10.

STANKO M., MIKLISOVÁ D., DE BELLOCQ J.G., MORAND S. 2002: Mammal density and patterns of ectoparasite species richness and abundance. Oecologia 131: 289-295.

UCHIKAWA K., ZHANG M.Y., O'CONNOR B.M., KLOMPEN H. 1994: Contribution to the taxonomy of the genus Spinturnix (Acari: Spinturnicidae), with the erection of a new genus, Emballonuria. Folia Parasitol. 41: 287-304.

ZAHN A., RUPP D. 2004: Ectoparasite load in European vespertilionid bats. J. Zool. 262: 1-9.

Accepted 9 January 2006 